\title{
NUTRIÇÃO MINERAL DE HORTALIÇAS. XIX - Absorção de Macro e Micronutrientes pela Cultura do Quiabeiro (Hibiscus esculentum L.) *
}

\author{
M. C. B. Costa ** \\ H. P. HAAG $* * *$ \\ J. R. SARRUge ***
}

\section{RESUMO}

O presente trabalho teve como objetivo estudar aspectos da nutrição mineral do quiabeiro (Hibiscus esculentus L.), no que concerne a: quantidades de macro e micronutrientes extraídos nas diversas fases do desenvolvimento, em duas variedades (Campinas 1 e Green Velvet).

Sementes de ambas variedades foram postas a germinar em vasos contendo sílica e irrigados com solução nutritiva completa. Plantas foram coletadas em períodos de 10 dias até aos 70 dias de idade, separadas em caule, folhas, flores e frutos. No material coletado foi determinado o peso da matéria seca e analizado quantitativamenta para macro e micronutrientes, com excessão do cloro.

Observou-se que o desenvolvimento em altura é identico em ambas as variedades; variedade Campinas 1 apresenta maior peso de matéria seca no final do ciclo; a extração dos nutrientes é lenta até aos: 20 dias, acentuando-se após este período até o final do ciclo, em ambas as variedades; a extração de potássio pela var. Green Velvet é aproximadamente o dobro da var. Campinas 1; a var. Campinas 1 extrai maiores quantidades de micronutrientes.

\section{INTRODUÇÃO}

No Brasil, grande importância vem tendo ultimamente a cultura do quiabeiro. No Estado de São Paulo, na zona principal produtora nos arredores de Campinas, encontram-se cultivos de até 12 hectares. No norte e nordeste do Brasil, locais onde o consumo desta hortaliça é mais generalizado encontram-se maior número de agricultores que produzem em larga escala esta hortaliça. Segundo CLOPTON e colaboradores (1948) e SPIVEY (1957), além do grande consumo no fa-

* Parte da Dissertação apresentada à E.S.A. "Luiz de Queiroz", U.S.P. para obtenção do título de Mestre pelo primeiro autor. Entregue para publicação 27/12/72.

** Seção de Botânica e Ecologia Vegetal do Instituto de Pesquisas Agronômicas do Estado de Pernambuco - Bolsista do CNPq.

*** Departamento de Química, E.S.A. "Luiz de Queiroz", U.S.P. 
brico de sopas, o fruto é comprado em grandes quantidades pelas indústrias para extração de óleo da semente, de boa qualidade para a alimentação humana.

Não encontrou-se na literatura estudos sobre a absorção dos nutrientes por esta espécie hortícola.

O objetivo do presente trabalho é: aquilatar o crescimento e a extração dos macro e micronutrientes pelo quiabeiro no cultivar" Campinas 1 e Green Velvet.

\section{MATERIAL E MÉTODOS}

Sementes de quiabeiro (Hibiscus esculentus L.) das variedades Campinas 1 e Green Velvet (1), foram postas a germinar em vasos de barro revestidos internamente com tinta plástica Epoxy, contendo aproximadamente $7 \mathrm{~kg}$ de sílica lavada por vaso. Em cada vaso foram postas a germinar 20 sementes de uma das variedades, mantendo-se o teor de umidade, com adições periódicas de água destilada.

Quando as plântulas atingiram $5 \mathrm{~cm}$ de altura, cinco dias após germinação, procedeu-se ao desbaste quanto à uniformidade, eliminando-se as de maior e menor desenvolvimento. A seguir passou-se a regar todas as plantas com solução nutritiva completa de SARRUGE (1970) (2) diluída com água destilada a 1:3. Dez dias após a germinação, procedeu-se à coleta da primeira amostragem que constou de 25 plantas de cada uma das variedades e elevou-se a concentração da solução nutritiva para $2: 3$. Finalmente, quinze dias após germinação as plantas passaram a ser regadas com solução completa sem diluição.

A partir deste momento as coletas de amostras de ambas as variedades foram realizadas de $10 \mathrm{em} 10$ dias, até aos 70 dias após a germinação, quando o quiabeiro já encontrava-se em plena frutificação. Todas as plantas antes de serem coletadas eram medidas na altura $(\mathrm{cm})$ do colo ao ápice, e posteriormente divididas em caule, folha, flores e frutos. Cada amostra compunha-se de número nunca inferior a 8 plantas. Após a secagem do material era determinado o peso da matéria seca $(\mathrm{g})$.

Durante o desenvolvimento da cultura, combateu-se o pulgão (Aphis gossypii) com pulverizações a alto volume de arprocarb 0,05\% usando-se o concentrado emulsionável a $20 \%$.

(1) Provenientes do Departamento de Botânica da E.S.A. "Luiz de Queiroz" São Paulo.

(2) (2) $\mathrm{KH}_{2} \mathrm{PO}_{4} \mathrm{M}-1 \mathrm{ml} / 1 ; \mathrm{KNO}_{3} \mathrm{M}-5 \mathrm{ml} / 1 ; \mathrm{Ca}\left(\mathrm{NO}_{3}\right)_{2} \mathrm{M}-5 \mathrm{ml} / 1 ; \mathrm{MgSO}_{4} \mathrm{M}-2 \mathrm{ml} / 1$; micronutrientes $1 \mathrm{ml} / 1$. 
O material vegetal logo após a coleta foi primeiramente lavado com água desmineralizada, seguindo-se com água desmineralizada contendo detergente neutro Alconox (3) ( $1 \mathrm{~g} / \mathrm{litro} / \mathrm{e}$ finalmente com água desmineralizapa. A seguir as amostras foram secas em estufa a $80^{\circ} \mathrm{C}$ e moídas em moínho Wiley com peneira n. ${ }^{\circ} 20$.

Foram obedecidos os seguintes métodos nas determinações químicas: nitrogênio pela técnica Kjeldahl - semi-micro, descrito em MALAVOLTA (1957).

No extrato nitro-perclórico do material foram seguidas as recomendações de LOTT e colaboradores (1956), para dosar o fósforo; sendo ainda determinadosno mesmo extrato os teores de potássio por fotometria de chama descrito em SARRUGE (1971). Cálcio, magnésio, cobre, zinco, ferro e manganês por espectrofotometria de absorção atômica (THE PERKIN-ELMER CORP, 1966). Enxofre por gravimetria, segundo CHAPMAN e colaborador (1061). Boro e molibdênio segundo JOHNSON e colaborador (1959).

\section{RESULTADOS E DISCUSSÃo}

\section{Crescimento}

No Gráfico n. ${ }^{0} 1$ e n. 2 em que são expostos a altura $(\mathrm{cm})$ e peso da matéria seca ( $\mathrm{g}$ ) plantas de cada uma das variedades pode-se verificar que as plantas da variedade Green Velvet tiveram um desenvolvimento maior de que a variedade Campinas 1 .

A curva de crescimento para variedade Green Velvet foi contínua sem deflexão até aos 60 dias, quando as plantas encontravam-se em plena frutificação. A variedade Campinas 1, sofre uma diminuiçãa no rítmo de crescimento, no início da frutificação, entre os 40 e 50 dias, crescimento este que se acentua aos 50 dias até 70 dias de idade. Enbora a variedade Green Velvet tivesse maior desenvolvimento apresentou-se um menor peso de matéria seca, confrontada variedade Campinas 1.

A produção de flores e frutos na variedade Green Velvet foi superior a variedade Campinas $1 \mathrm{em}$ cerca de $6 \mathrm{~g}$ aos 70 dias.

Teor porcentual dos macronutrientes durante o desenvolvimento das plantas.

Através das análises químicas da matéria seca das diversas amostras, das variedades Campinas 1 e Green Velvet, tornou-se possível a

(3) Alconox, Inc. New York, U.S.A. 
obtenção dos teores médios dos macronutrientes no caule, folhas, flores e frutos.

O Quadro 1 apresenta os teores em porcentagens dos macronutrientes em ambas as variedades, em função do peso da matéria seca. Observa que de um modo geral as porcentagens dos nutrientes são mais elevados na variedade Green Velvet.

\section{Nitrogênio}

Para este nutriente as maiores concentrações encontraram-se nas partes superiores das plantas, principalmente flores e frutos, devido a sua fácil translocação. Na literatura encontra-se inúmeras referências atestando a fácil translocação do nitrogênio, BEEVERS e colaborador (1969), JONES (1966), entre outros.

A concentração deste nutriente em ambas as variedades nas folhas à medida que as plantas se desenvolvem. No caule a porcentagem de $\mathrm{N}$ aumenta até o início da frutificação decaindo após este estádio. Nos frutos apresenta-se com pouca variação; sendo que nas flores ocorre uma ascenção com a idade da planta.

\section{Fósforo}

Este nutriente apresentou sempre maiores concentrações nas porções superiores, devido a sua fácil translocação. A facilidade de se translocar é citada na literatura, por BINGHAM (1966); BOLLARD e colaborador (1966), entre outros. A concentração deste nutriente em ambas as variedades decresce no caule à medida que a planta evolui. Nas folhas a porcentagem aumenta até o fim do ciclo. Nas flores apresenta pouca variação; nos frutos apresenta uma elevação dos teores com a idade das plantas.

\section{Potássio}

Apresentou-se móvel dentro da planta, em maior concentração nos frutos. A translocação do potássio é conhecida na literatura em inúmeros artigos, entre outros (HEWITT, 1963; ULRICH e co-aborador, 1966). Digno de nota é a diferença dos teores porcentuais entre as duas variedade Green Velvet apresentado mais do dobro da concentração da variedade Campinas 1. A concentração em ambas as variedades decresce no caule à medida que a planta evolui. Nas folhas enquanto na variedade Campinas 1 diminui com a idade da planta, na variedade Green Velvet aumenta; nas flores ocorrem o mesmo, ou seja, diminuição com a idade na variedade Campinas 1, e aumenta com a idade na variedade Green Velvet. 


\section{Cálcio}

Como se pode verificar o cálcio é pouco móvel dentro da planta, sendo que os frutos apresentam porcentagem inferior daquela encontrada no caule em ambas as variedades. Esta pequena mobilidade deste nutriente, tem sido citada, por inúmeros autores, em outros espécies vegetais CHAPMAN (1966), GAUCH (1957) entre outros. As folhas aumentam com a idade o teor porcentual. Para as flores a concentração diminui com a idade na variedade Campinas 1 e aumenta na variedade Green Velvet. A concentração no fruto diminui com a idade em ambas as variedades.

\section{Magnésio}

Encontra-se na literatura referências atestando a fácil translocação do magnésio (EMBLETON, 1966; HEWITT, 1963).

Como observou-se para o potássio, o magnésio no quiabeiro, comportou-se de mobilidade intermediária, FERNANDES (1971), e BUKOVAC e colaborador (1957) verificaram o mesmo em pimentão e feijoeiro. Os teores porcentuais no caule diminui com a idade. Nas folhas na variedade Campinas 1, aumenta até aos 40 dias e em seguida diminui com a idade, na variedade Green Velvet diminui com a idade. As flores em ambas as variedades aumenta a concentração com a idade. Os frutos mantêm a mesma concentração independente da idade.

\section{Enxofre}

Referências encontradas na literatura, aludem a mobilidade intermediária do enxofre nas plantas, em outras espécies hortículas (BUKOVAC e colaborador, 1957; FERNANDES, 1971; HAAG, 1970).

Para o quiabeiro o enxôfre também mostrou-se relativamente móvel apresentando maiores concentrações nas partes superiores da planta. A concentração deste nutriente em ambas as variedades decresce no caule à medida que as plantas desenvolvem-se. No caule na variedade Campinas 1 decresce com a idade, na variedade Green Velvet cresce até os 50 dias decrescendo daí por diante. Nas flores de ambas as variedades decresce com a idade. Nos frutos a porcentagem é crescente em ambas as variedades com a idade.

\section{Extração dos Macronutrientes durante o desenvolvimento.}

Para melhor aquilatar-se as quantidades dos macronutrientes, ex- 


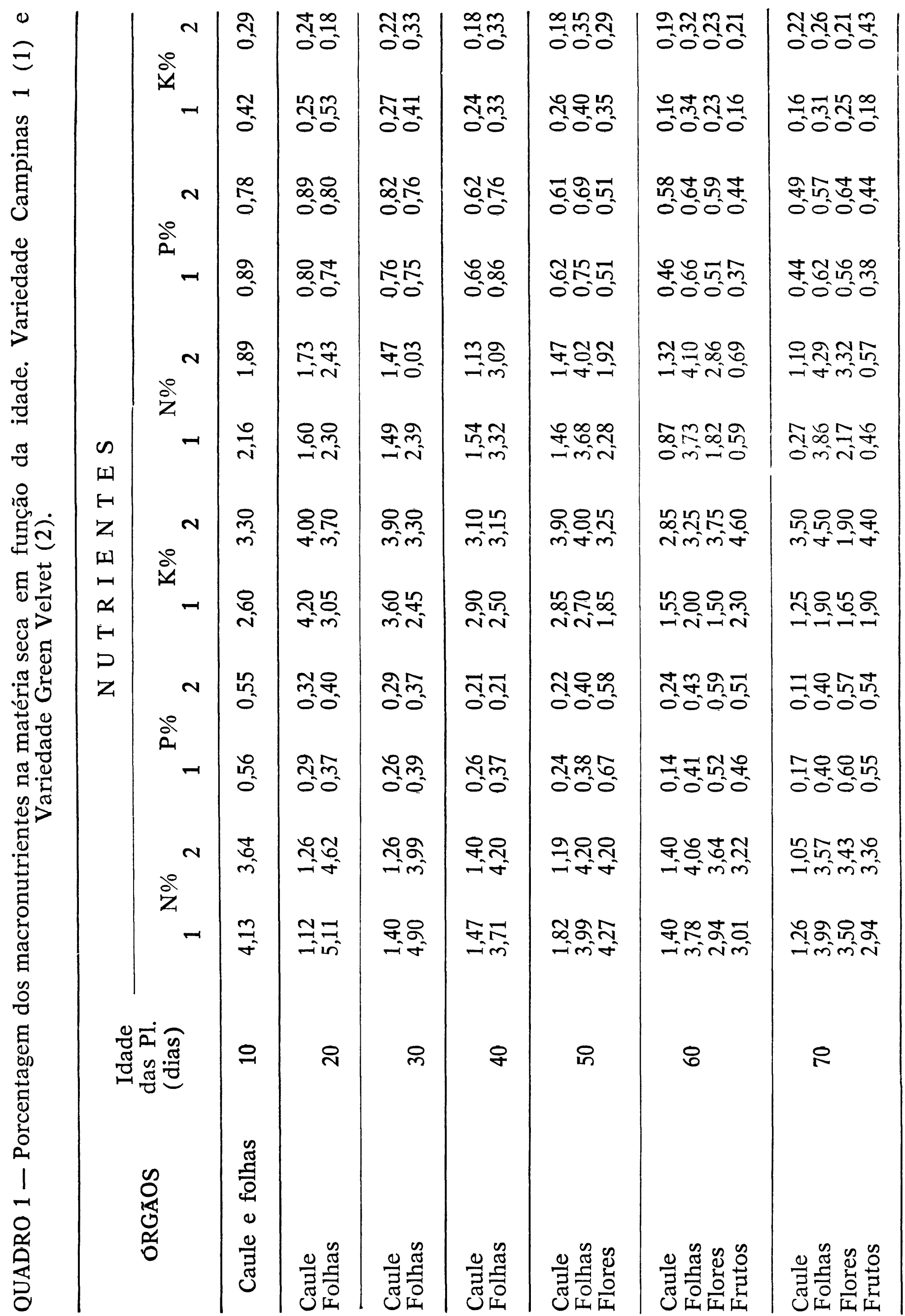


traídos pelas duas variedades de quiabeiro durante o crescimento, organizou-se o Quadro 2 e o Gráfico n..$^{\circ}$ (A, B, C, D e E).

Para uma melhor visualização os dados são apresentados em função de uma plantação contendo 20.000 plantas/ha que segundo a literatura é a população normal para a cultura no Estado de São Paulo (BERNARDI, 1957).

A extração dos nutrientes é nas diversas fases de crescimento semelhante em ambas as variedades, com exceção do potássio. A variedade Green Velvet possui mais capacidade de extração do potássio, superando grandemente a variedade Campinas $1 \mathrm{em}$ todas as fases de crescimento. Verificou-se que a extração é mínima até os 20 dias, quando ocorre um aumento crescente na extração dos nutrientes por todas as partes da planta, em ambas as variedades.

Digno de nota, é o fato de que a extração de potássio pela variedade Green Velvet é superior a quantidade de nitrogênio extraída por ambas as variedades.

SILVEIRA e colaboradores (1971) recomendaram, baseados em MAKISHIMA (1969), a aplicação do nitrogênio parcelado em 3 ou 4 aplicações a partir do $30 .^{\circ}$ dia após o plantio, época em que a extração dos macronutrientes acentua-se coincidindo com o florescimento e início da frutificação. É digno de nota a grande diferença na exportação total de nutrientes pelos frutos entre as variedades aos 70 dias de idade; assim, a variedade Green Velvet exporta $37,14 \mathrm{~kg} / \mathrm{ha}$ contra a variedade Campinas 1 que exporta $16,16 \mathrm{~kg} / \mathrm{ha}$. A quantidade de nutriente que permanece no campo é aproximadamente idêntica nas duas variedades $(62,5 \mathrm{~kg} / \mathrm{ha})$. Embora ambas as variedades sejam exigentes em cálcio, muito pouco é exportado através da produção de frutos, como se pode observar no Gráfico n.. $3(\mathrm{G})$.

\section{Teor dos micronutrientes em ppm durante o desenvolvimento das plantas.}

Através das análises químicas do material seco, das variedades Campinas 1 e Green Velvet, tornou-se possível a obtenção dos teores médios dos micronutrientes no caule, folhas, flores e frutos.

Pelo exame do Quadro 3 pode-se verificar os teores em ppm dos micronutrientes em ambas as variedades expressos em função do peso da matéria seca, durante o desenvolvimento em ambas as variedades.

\section{Boro}

Para este nutriente verifica-se que os maiores teores encontram- 
se nas partes superiores do vegetal, fato já constatado no alho por SILVA e colaboradores (1970). No caule da variedade Campinas 1, os teores diminuem com a idade, sendo que na variedade Green Velvet aumentam. Nos frutos os teores diminuem com a idade, em ambas as variedades.

\section{Manganês}

O manganês apresentou-se com os teores mais elevados nas partes superiores da planta, resultados idênticos foram encontrados para a cultura do alho por SILVA e colaboradores (1970). Nos caules de ambas as variedades os teores diminuem com o desenvolvimento da cultura. Nas folhas e flores das duas variedades aumentam os teores com a idade da planta. Nos frutos da variedade Campinas 1 os teores aumentam com a idade, enquanto que na variedade Green Velvet diminuem.

\section{Molibdênio}

Para o molibdênio, também encontram-se os teores mais elevados nas partes superiores das plantas. No caule da variedade Campinas 1, os teores aumentam até aos 60 dias, e na variedade Green Velvet decresce com a idade. Nas folhas da variedade Campinas 1 os teores crescem até os 60 dias, enquanto na variedade Green Velvet, os teores crescem apenas até os 50 dias, para em seguida decrescerem. Nos frutos a concentração de molibdênio decrescem em ambas as variedades com o amadurecimento.

\section{Ferro}

Apresenta também os teores mais elevados nas partes superiores da planta, fato esse verificado na cultura do alho, por SILVA e colaboradores (1970).

Os teores no caule da variedade Campinas 1 aumentam até os 50 dias para então decrescerem e na variedade Green Velvet os teores aumenta até os 60 dias de idade. Nas folhas, flores e frutos de ambas as variedades os teores aumentam com a idade. 


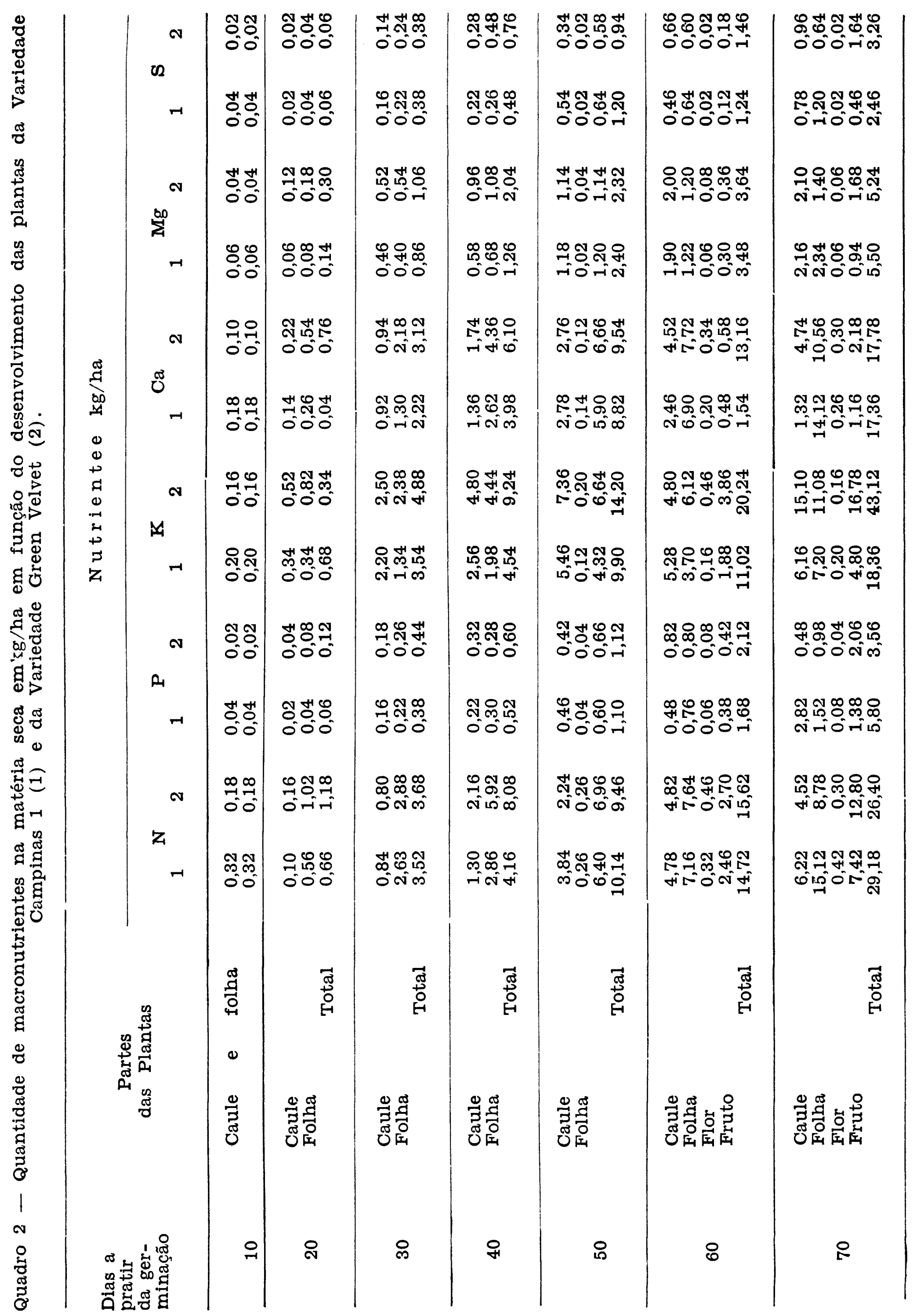



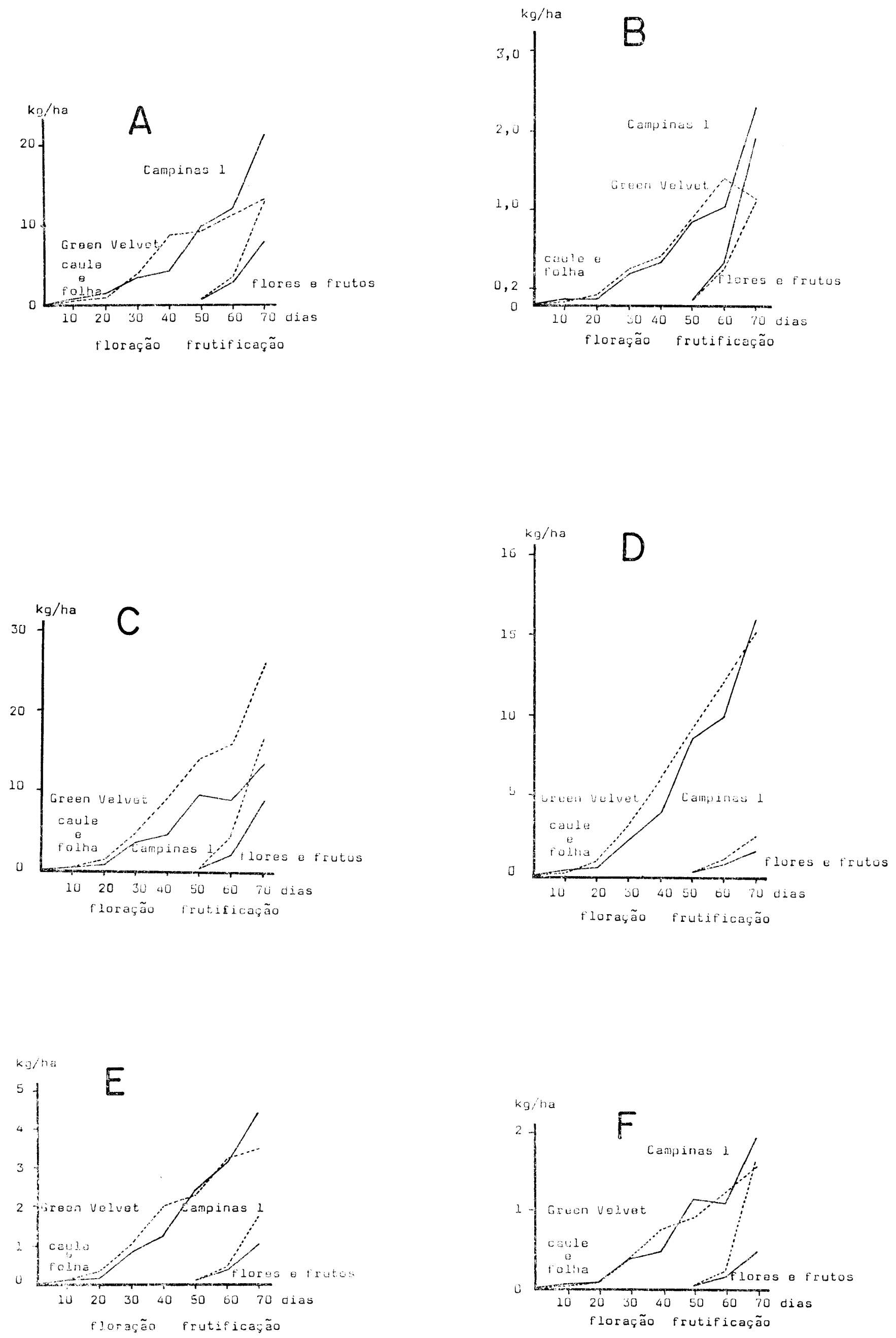

Figura 3 - Extração dos macronutrientes em $\mathrm{Kg} / \mathrm{ha}$ em função do desenvolvimento da cultura - N (A); P (B); K (C); Ca (D); Mg (E); S (F). 


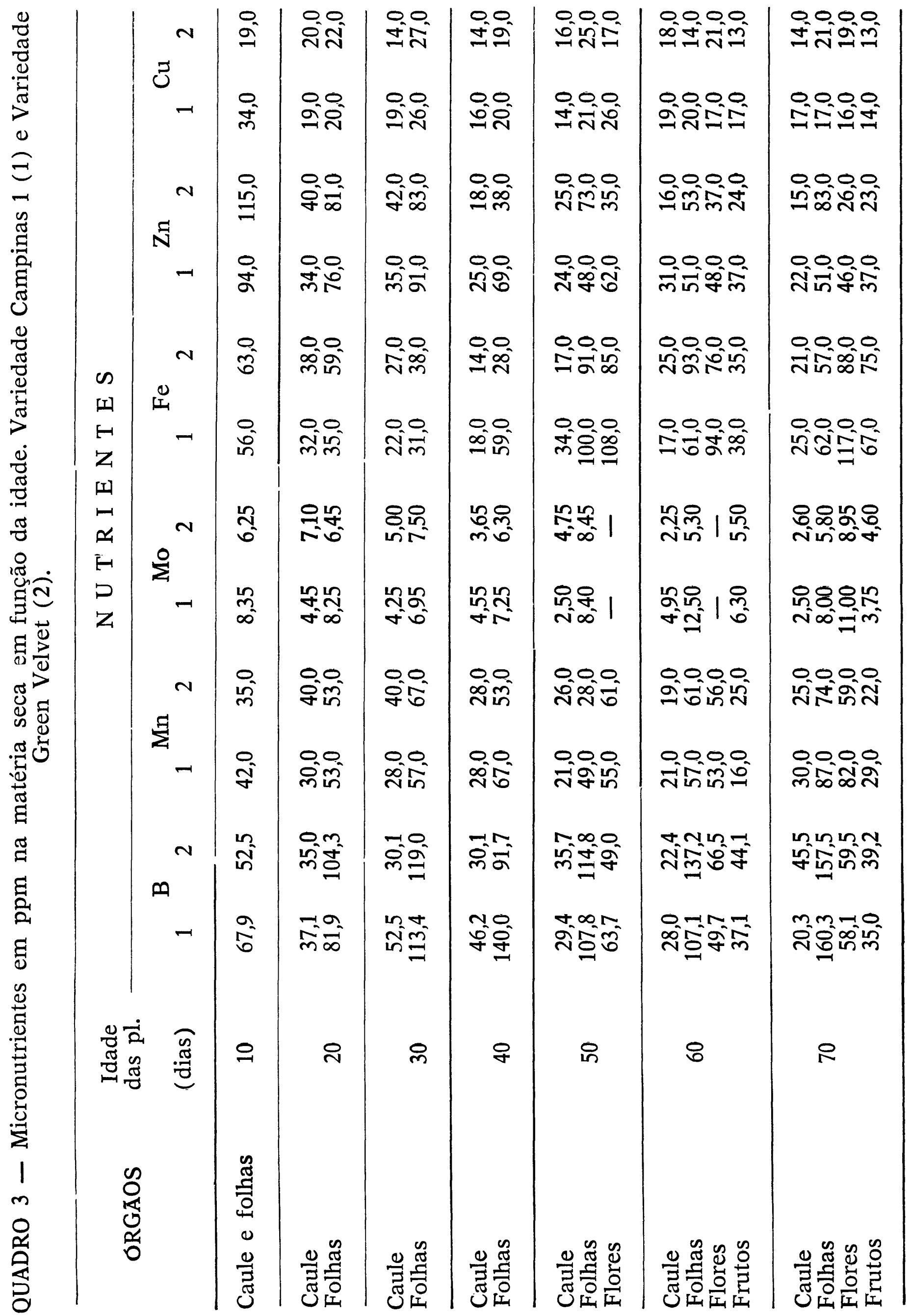


Anais da E.S.A. "Luiz de Queiroz"

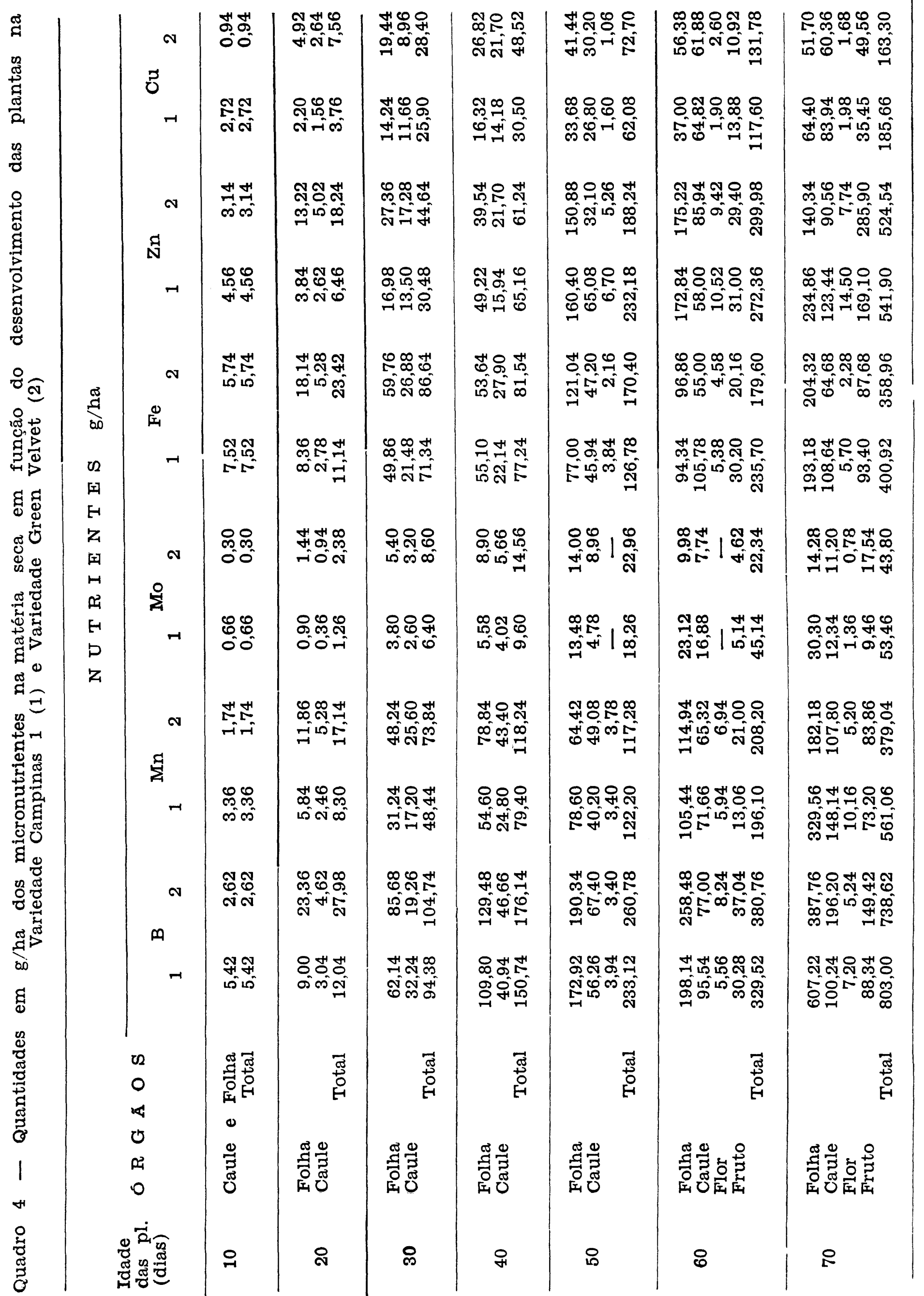



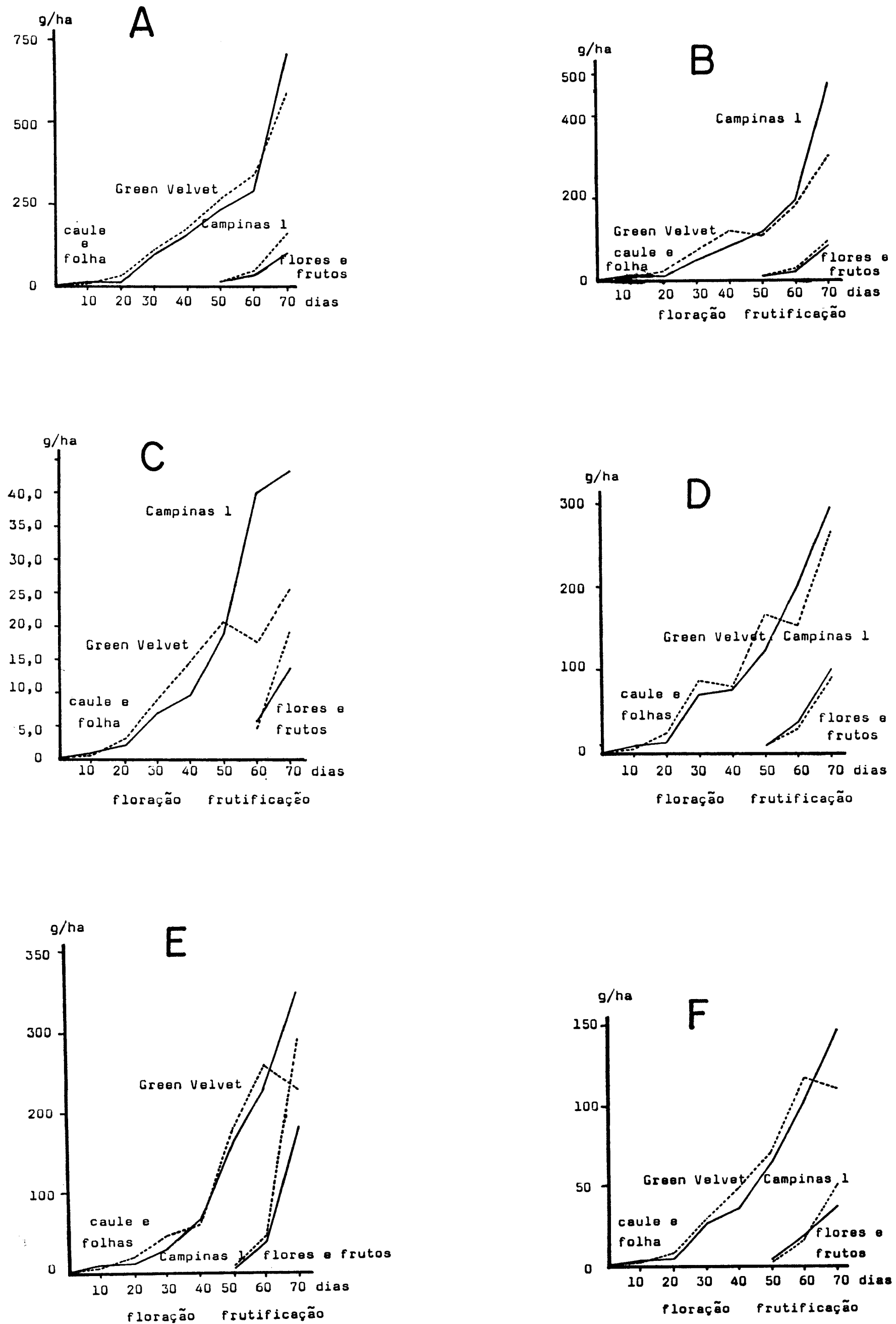

Figura 4 - Extração dos macronutrientes em g/ha em função do desenvolvimento da cultura - B (A); Cu (B); Fe (C); Mn (D); Mo (E); Zn (F). 


\section{Zinco}

O zinco apresenta-se em maiores concentrações nas partes superiores do vegetal. Os teores dos caules de ambas as variedades decrescem com a idade. Nas folhas da variedade Campinas 1 diminui o teor com a idade sendo que, na variedade Green Velvet ocorre o inverso. Nas flores de ambas as variedades os teores decrescem com a idade. Nos frutos o teor de zinco não sofreu alteração de níveis.

\section{Cobré}

A concentração de cobre em todos os órgãos de ambas as variedades apresentou-se com pouca amplitude, oscilando de um órgão para outro em torno de $5 \mathrm{ppm}$.

Extração dos micronutrientes durante o desenvolvimento das plantas.

Para uma melhor visualização das quantidades dos micronutrientes, extraídos pelas duas variedades de quiabeiro, durante o seu desenvolvimento organizou-se o Quadro 4 e o Gráfico n. ${ }^{\circ} 4$ (A, B, C, D, E, F).

Os dados são apresentados em g/ha, em função de uma plantação contendo 20.000 plantas/ha.

A extração dos micronutrientes foi nas diversas fases do desenvolvimento semelhantes nas duas variedades, com exceção do manganês em que a variedade Campinas 1 demonstrou ter maior capacidade de extração, superando no final do ciclo a variedade Green Velvet em aproximadamente $180 \mathrm{~g}$.

É digno de nota que embora aos 70 dias a variedade Campinas 1 , supere em quantidade total de micronutrientes a variedade Green Velvet a exportação pelos frutos da variedade Green Velvet é de 673,96 g/ha, enquanto que na variedade Campinas 1 é de 468,84 g/ha. A quantidade de nutrientes que retorna ao campo através dos restos da cultura, na variedade Campinas 1 é de 2.077,16 g e na variedade Green Velvet, $1.534,30 \mathrm{~g}$. Os micronutrientes são extraídos em $\mathrm{g} / \mathrm{ha}$ aos 70 dias na seguinte ordem decrescente:

a) Variedade Green Velvet: $\mathrm{B}(738,62) ; \mathrm{Zn}(524,54) ; \mathrm{Mn}(379,04)$; $\mathrm{Fe}(358,96) ; \mathrm{Cu}(163,30)$ e $\mathrm{Mo}(43,80)$. ?

b) Variedade Campinas 1: (B(803,00); $\operatorname{Mn}(561,06) ; \operatorname{Zn}(541,90)$; $\mathrm{Fe}(400,92) ; \mathrm{Cu}(185,66)$ e $\mathrm{Mo}(53,46)$. 


\section{CONCLUSÕES}

O desenvolvimento em altura é idêntico em ambas as variedades.

A variedade Campinas 1 apresenta maior peso de matéria seca em confronto com a variedade Green Velvet no final do ciclo.

A extração dos macro e micronutrientes é lenta até aos 20 dias de idade das plantas, acentuando-se após este período até o final do ciclo em ambas as variedades.

A extração de potássio pela variedade Green Velvet supera em aproximadamente $100 \%$ a variedade Campinas 1 .

A extração de manganês é superior na variedade Campinas 1 , no final do ciclo.

São pequenas as diferenças de extração dos nutrientes no final do ciclo, pela variedade Campinas 1 (1) e Green Velvet (2).

A extração dos macronutrientes total é superior na variedade de Green Velvet.

A variedade Campinas 1 extrai quantidades superiores dos micronutrientes em confronto com a variedade Green Velvet.

\section{SUMMARY}

MINERAL NUTRITION OF VEGETABLE CROPS. XIX.

Absorption of macro and micronutrientes by okra plants.

Plants of the varieties. - Campinas 1 and Green Velvet, were cultivated under nutrition solution conditions (SARRUGE, 1970). Periodically, every 10 days, from the $10^{\text {th }}$ day up plants were harvested, divided into stalks, leaves, flowers, fruits and analysed for N, P, K, Ca, Mg, S, B, Cu, Fe, Mn, Zn and Mo.

\section{Conclusions :}

Okra plants of the variety Campinas 1 showed a higher dry matter production in confront with the variety Green Velvet at the final stage of growth;

The extraction of nutrients by plants of both varieties was rather small until the age of 20 days;

The extraction on $\mathrm{K}$ by the variety Green Velvet was superior in $100 \%$ when compared to the variety Campinas 1 .

The variety Green Velvet has a greater demand in macronutrients than the variety Campinas ${ }^{1}$; 
In contrast the variety Campinas 1 extracted superior quantities of the micronutrientes than the variety Green Velvet.

On ha of okra plants $(20,000)$ removed the following quantities in nutrients:

\begin{tabular}{|c|c|c|c|c|c|c|}
\hline Nutrient & \multicolumn{2}{|c|}{$\begin{array}{c}\mathrm{kg} / \mathrm{ha} \\
\text { stalk }+ \text { leaves }\end{array}$} & \multicolumn{2}{|c|}{$\begin{array}{c}\mathrm{kg} / \mathrm{ha} \\
\text { flowers }+ \text { frutts }\end{array}$} & \multicolumn{2}{|c|}{$\begin{array}{l}\mathrm{kg} / \mathrm{ha} \\
\text { total }\end{array}$} \\
\hline $\mathbf{N}$ & 21.54 & 13.30 & 7.84 & 13.10 & 29.18 & 26.40 \\
\hline K & 13.36 & 26.18 & 5.00 & 16.94 & 18.36 & 43.12 \\
\hline $\mathrm{Ca}$ & 15.94 & 15.30 & 1.42 & 2.48 & 17.36 & 17.78 \\
\hline $\mathrm{P}$ & 4.34 & 1.46 & 1.46 & 2.10 & 5.80 & 3.56 \\
\hline $\mathrm{Mg}$ & 4.50 & 3.50 & 1.00 & 1.74 & 5.50 & 5.24 \\
\hline \multirow[t]{3}{*}{$S$} & 1.98 & 1.60 & 0.48 & 1.66 & 2.46 & 3.26 \\
\hline & & & & Total & 78.66 & 99.36 \\
\hline & \multicolumn{2}{|c|}{$\mathrm{g} / \mathrm{ha}$} & \multicolumn{2}{|c|}{ g/ha } & \multicolumn{2}{|c|}{$\mathrm{g} / \mathrm{ha}$} \\
\hline B & 707.46 & 583.96 & 95.54 & 154.66 & 803.00 & 738.62 \\
\hline $\mathrm{Mn}$ & 477.70 & 289.98 & 83.36 & 89.06 & 561.06 & 379.04 \\
\hline $\mathrm{Zn}$ & 358.20 & 230.90 & 183.60 & 293.64 & 541.80 & 524.54 \\
\hline $\mathrm{Fe}$ & 301.82 & 269.00 & 99.10 & 89.96 & 400.92 & 358,96 \\
\hline $\mathrm{Cu}$ & 148.34 & 112.06 & 37.32 & 51.24 & 185.66 & 163.20 \\
\hline \multirow[t]{2}{*}{ Mo } & 42.64 & 25.48 & 10.82 & 18.32 & 53.46 & 43.80 \\
\hline & & & & Total & 2.544 .90 & 2.208 .16 \\
\hline
\end{tabular}

\section{LITERATURA CITADA}

BEEVERS, L. \& R. H. HAGEMAN, 1969. Nitrate reduction in higher plants. A. Rev. Pl. Phys., 20:495-522.

BERNARDI, J. B., 1957. Instruções para a cultura do quiabeiro. Boletim n.' 96 do I.A.C. Campinas, S.P.

BINGHAM, F. T., 1966. Phosphorus. Em Diagnostic Criteria for Plants and soils. ed. por H. D. CHAPMAN, University of California, Div. of Agric. Sciencies. California, U.S.A.

BOLLARD, E. G. \& G. W. BUTTLER, 1966. Mineral Nutrition of Plants. A. Rev. Pl. Phys., 17:77-109. 
BUKOVAC, M. J. \& S. H. WITTWER, 1957. Absorption and Mobility of Fo. liar Applied Nutrients. Pl. Physiol. USA, 32:428-435.

CHAPMAM, H. D. \& P. F. PRATT, 1961. Methods of Analysis for soils plant and Waters. Univ. of California. Div. of Agric. Sciencies. U.S.A.

EMBLENTON, T. W. 1966. Magnésium. Em Diagnostic Critéria for Plants and soils, ed. por H. D. CHAPMAM, Univ. of California, Div. of Agric. Sciencies California, U.S.A.

FERNANDES, P. D., 1971. Estudos de Nutrição Mineral de Pimentão (Capsicum annuin, L.) Variedade Avelar e Ikeda. Absorção e Deficiências de Macronutrientes. Tese (datilografada), E.S.A. "Luiz de Queiroz", U.S.P., Piracicaba - S.P.

GAUCH, H. G., 1957 - Mineral Nutrition of Plants. A. Rev. Pl. Physiol., 8: 31-64.

HAAG, H. P., 1965. Estudos de Nutrição Mineral da Cana de açúcar (Saccharum officinarum, L.), variedade CB 41-76, cultivado em solução nutritiva. Tese (mimeografada), E.S.A. "Luiz de Queiróz", U.S.P. Piracicaba, S.P.

HEWITT, E. J., 1963 - The Essential Nutrient Elements: Requirements and Interactions in Plants. Em: Physiology, ed. for F. C. STEWARD, Academic Press, N. York and London.

JOHNSON, C. M. \& A. ULRICH, 1959. II Analytical methods for use in plant analysis. Calif. Agr. Sta. Exp. Bull. '766.

JONES, W. W., 1966 - Nitrogen. Em Diagnostic Criteria for Plants and Soils, ed. por H. D. CHAPMAM. Univ. of California, Div. of Agric. Sciencies. California, U.S.A.

LOTT, W. L.; J. P. NERY; J. R. GALLO \& J. C. MEDCALF, 1956 - A técnica da análise foliar aplicada ao cafeeiro. Inst. Agronomico, Bol. 79, Campinas, S.P.

MAKISHIMA, N., 1969. Horta doméstica. Instruções práticas. SCR n. 61. CATI - Campinas, S.P.

MALAVOLTA, E., 1957 - Práticas de Química Orgânica e Biológica. E.S.A. "Luiz de Queiróz", Piracicaba, S.P.

SARRUGE, J. R., 1970. Práticas de Nutrição e Adubação das Plantas Cultivadas (mimeo.). E.S.A. "Luiz de Queiróz" - U.S.P. Piracicaba-S.P.

SILVA, N. D.; G. D. D. OLIVEIRA; E. F. C. VASCONCELLOS \& H. P. HAAG, 1970 - Nutrição Mineral de Hortaliças. XI Absorção de Nutriente pela cultura do alho. Solo, LXII 1:7-17.

SILVEIRA, R. I.; F. de A. F. DE MELLO;M. O. C. B. SOBRINHO \& S. ARZOLLA, 1971 - Adubos e Adubação das Principais Culturas Brasileiras. Vol. 2 Departamento de Solos e Geologia. E. S. A. "Luiz de Quei-

róz", Piracicaba - S.P.

SPIVEY, C. D.; O. J. WOODARD \& W. D. WOODARD, 1957. The production of okra in South Georgia. Bull Ga. Agric. Exp. Stats 44:

THE PERKIN-ELMER CORP., 1966. Analitycal Methods for Atomic Absorption Spectrophotometry. Perkin-Elmer Corpor. Connecticut, U.S.A.

ULRICH, A. \& K. OHKI, 1966. Potassium.' Em Diagnostic Criteria for Plants and Soils, ed. for H. D. CHAPMAM, Univ. of California. Div. of Agric. Sciencies. California. U.S.A. 
